\title{
Premedication before intubation in UK neonatal units
}

Simon Whyte, Ginny Birrell, Jonathan Wyllie

\begin{abstract}
Aims-To establish the extent and type of premedication used before intubation in neonatal units in the United Kingdom. Methods-A structured telephone survey was conducted of 241 eligible units. Units were subdivided into those that routinely intubated and ventilated babies (routine group) and those that transferred intubated and ventilated babies (transfer group).

Results-Of the units contacted, 239 (99\%) participated. Only $88 / 239(37 \%)$ gave any sedation before intubating on the unit and only $34 / 239$ (14\%) had a written policy covering this. Morphine was used most commonly (66\%), with other opioids and benzodiazepines used less frequently. Of the 88 units using sedation, $19(22 \%)$ also used paralysis. Suxamethonium was given by $10 / 19(53 \%)$ but only half of these combined it with atropine. Drug doses varied by factors of up to 200 , even for commonly used drugs.

Conclusion-Most UK neonatal units do not sedate babies before intubating, despite evidence of physiological and practical benefits. Only a minority have written guidelines, which prohibits auditing of practice.
\end{abstract}

(Arch Dis Child Fetal Neonatal Ed 2000;82:F38-F41)

Anaesthetics,

Liverpool Women's

Hospital,

Liverpool L8 7 SS

S Whyte

Department of Paediatrics,

South Cleveland

Hospital,

Marton Road,

Middlesbrough

TS4 3BW

J P Wyllie

G Birrell

Correspondence to: Dr Simon Whyte Email: sdwhyte@bigfoot.com

Accepted 14 June 1999

Keywords: intubation; premedication; sedation

Laryngoscopy and intubation are noxious stimuli that can provoke profound cardiovascular stress $^{1}$ as well as choking, gagging, coughing and laryngospasm in patients who are inadequately sedated for the procedure. These protective airway reflexes raise intrathoracic pressure, reducing venous drainage from the head and neck. The increase in systemic arterial pressure, ${ }^{2-8}$ combined with the decrease in venous return, raises intracranial pressure. $^{24-689}$ Various anaesthetic drugs, including supra-analgesic doses of fentanyl,

Table 1 Numbers (\%) of units with policies or regular practices for elective and emergency intubations/reintubations

\begin{tabular}{|c|c|c|c|}
\hline & $\begin{array}{l}\text { Routine } \\
(n=190)\end{array}$ & $\begin{array}{l}\text { Transfer } \\
(n=49)\end{array}$ & $\begin{array}{l}\text { Total } \\
(n=239)\end{array}$ \\
\hline Written policy for elective intubation/reintubation & $31(16)$ & $3(6)$ & $34(14)$ \\
\hline Also used for emergency intubation/reintubation & $18(9)$ & $1(2)$ & $19(8)$ \\
\hline $\begin{array}{l}\text { Regular practice for elective intubation/reintubation } \\
\text { (no written policy) }\end{array}$ & $43(23)$ & $7(14)$ & $50(21)$ \\
\hline Also used for emergency intubation/reintubation & $15(8)$ & $3(6)$ & $18(8)$ \\
\hline Written policy only for emergency intubation/reintubation & & $1(2)$ & $1(0.4)$ \\
\hline Regular practice only for emergency intubation/reintubation & $3(2)$ & & $3(1)$ \\
\hline No sedation for any intubation/reintubation & $113(59)$ & $38(78)$ & $151(63)$ \\
\hline
\end{tabular}

Table 2 Sedatives used by UK neonatal units before intubation

\begin{tabular}{lclc}
\hline & $\begin{array}{l}\star \text { Routine } \\
(\%)(n=77)\end{array}$ & $\begin{array}{l}\text { Transfer (\%) } \\
(n=11)\end{array}$ & $\begin{array}{l}\star \text { Total (\%) } \\
(n=88)\end{array}$ \\
\hline Morphine alone & $29(38)$ & $8(73)$ & $37(42)$ \\
Morphine + other† & $20(26)$ & $1(9)$ & $21(24)$ \\
Morphine: total & $49(63)$ & $9(82)$ & $58(66)$ \\
Fentanyl alone & $4(5)$ & & $4(4.5)$ \\
Fentanyl + other & $4(5)$ & & $4(4.5)$ \\
Fentanyl: total & $8(10)$ & $1(9)$ & $8(9)$ \\
Diamorphine & $11(14)$ & & $12(14)$ \\
Diazepam alone & $4(5)$ & & $4(4.5)$ \\
Diazepam + opioid & $6(8)$ & & $6(7)$ \\
Diazepam: total & $10(13)$ & & $10(11.5)$ \\
Midazolam alone & $4(5)$ & & $4(4.5)$ \\
Midazolam + opioid & $2(3)$ & & $2(2)$ \\
Midazolam: total & $6(8)$ & & $6(6.5)$ \\
Ketamine & $1(1)$ & $1(9)$ & $1(1)$ \\
Phenobarbitone & & $1(1)$ \\
\hline
\end{tabular}

${ }^{\star}$ Sum of percentages exceeds $100 \%$ because some units give opioids and benzodiazepines.

†See figure 1.

alfentanil, and remifentanil, blunt these responses in adults and children.

In 1992 Ziegler and Todres $^{10}$ reported a study of neonatal practice in the United States which found that $57 \%$ and $77 \%$ of respondents, respectively, never used sedation or muscle relaxants. To our knowledge there are no comparable data for the UK. This study aimed to establish the extent to which sedation for intubation is currently practised in UK neonatal units.

\section{Methods}

In September 1998 a list of all known UK neonatal intensive care units, neonatal units, and special care baby units was obtained from CMA Medical Data Ltd (Cambridge Research Laboratories). All 245 units listed were contacted by telephone over the next six weeks. Wherever possible, the contact was made with the sister in charge of the unit at the time, to maintain consistency and to ensure that the interviewee would be aware of policies where they existed. On each occasion the investigator (SDW or VLB) explained the purpose of the survey. Verification of identity was available via call back to switchboard and by provision of GMC number. Permission was obtained to enquire about each unit's practice and, following consent, a prepared questionnaire was completed.

Units were subdivided into those that routinely intubated and ventilated babies (routine group) and those that transferred intubated and ventilated babies (transfer group). Analysed data are presented for the whole population of neonatal units and the two subgroups. 


\section{Results}

All 245 units listed were contacted. Two declined to participate and three others had relocated their services. One further unit did not accept any premature deliveries. The sample therefore comprised 239 units, of whom 190 were in the routine group.

PROVISION OF SEDATION

Table 1 summarises the questionnaire data, illustrating that $63 \%$ of all units and $59 \%$ of the routine group gave no sedation before intubating on the unit. The overall average was increased by the transfer group, $78 \%$ of whom gave no sedation before intubating. There were $34 / 239$ units (14\%) with a formal written policy for sedating before elective intubation, with $31 / 190(16 \%)$ in the routine group, and $3 / 49(6 \%)$ in transferring units.

Overall, 8\% (19/239) of units had a written policy that was applied during elective and emergency intubations on the neonatal unit. A further $8 \%(18 / 239)$ routinely gave sedation before all intubations but did not have a written policy.

\section{Key messages}

- There is good evidence of physiological and practical benefit when neonates are sedated before intubation, and no evidence that it is harmful.

- Only $37 \%$ of UK neonatal units routinely sedate babies before intubating them on the unit.

- Only $14 \%$ of units have formal guidelines for sedation before intubation, prohibiting audit of practice.

DRUGS USED

Eighty eight of the 239 units (37\%) gave some form of sedation before intubation as detailed in table 2. Morphine was used most often (58/ $88 ; 66 \%)$. Around two thirds of these used it as the sole drug administered, but this was more representative of the transferring units, $73 \%$ of whom gave morphine in isolation, compared with $38 \%$ of units that routinely ventilated.

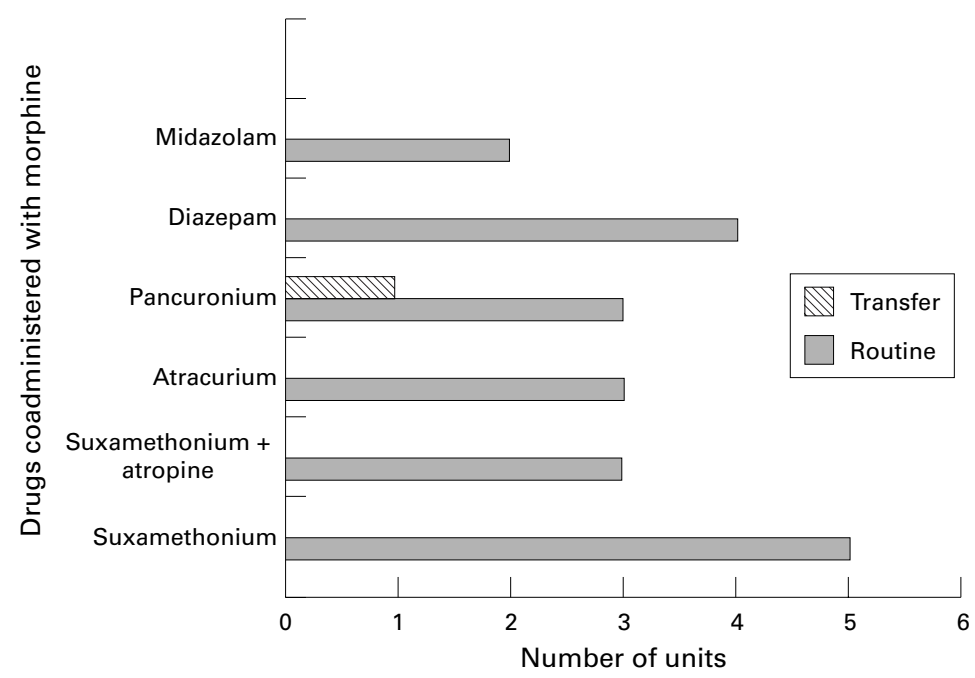

Figure 1 Prevalence of co-administration of drugs with morphine in UK neonatal units.
Table 3 Use of muscle relaxants by routine group UK neonatal units

\begin{tabular}{ll}
\hline Relaxant & $n(\%)$ \\
\hline Suxamethonium & $10(56)$ \\
co-administered with: & \\
$\quad$ morphine + atropine & 5 \\
morphine & 3 \\
fentanyl & 1 \\
$\quad$ ketamine & 1 \\
Atracurium & $4(22)$ \\
co-administered with: & 3 \\
morphine & 1 \\
fentanyl & $3(17)$ \\
cancuronium & \\
mo-administered with: & 3 \\
Vecuronine & $1(6)$ \\
\hline
\end{tabular}

*One transferring unit also used pancuronium, in combination with morphine.

Table 4 Dose ranges and modes for premedication drugs in UK neonatal units

\begin{tabular}{lll}
\hline Drug & Range & Mode \\
\hline Morphine & $5-1000 \mathrm{mcg} / \mathrm{kg}$ & $100 \mathrm{mcg} / \mathrm{kg}$ \\
Diamorphine & $10-250 \mathrm{mcg} / \mathrm{kg}$ & $50 \mathrm{mcg} / \mathrm{kg} ; 50-100 \mathrm{mcg} / \mathrm{kg}$ \\
Fentanyl & $1-20 \mathrm{mcg} / \mathrm{kg}$ & $10 \mathrm{mcg} / \mathrm{kg}$ \\
Diazepam & $30-300 \mathrm{mcg} / \mathrm{kg}$ & $300 \mathrm{mcg} / \mathrm{kg}$ \\
Midazolam & $50-200 \mathrm{mcg} / \mathrm{kg}$ & No mode \\
Atracurium & No range & $500 \mathrm{mcg} / \mathrm{kg}$ \\
Pancuronium & No range & $100 \mathrm{mcg} / \mathrm{kg}$ \\
Suxamethonium $1-3 \mathrm{mg} / \mathrm{kg}$ & $1-2 \mathrm{mg} / \mathrm{kg} ; 2 \mathrm{mg} / \mathrm{kg}$ \\
Atropine & $10-20 \mathrm{mcg} / \mathrm{kg}$ & $10 \mathrm{mcg} / \mathrm{kg} ; 20 \mathrm{mcg} / \mathrm{kg}$ \\
\hline
\end{tabular}

Only one transferring unit co-administered morphine $(11 \%)$, while a quarter of all routinely ventilating units gave an additional drug with morphine (fig 1 ).

In the 30/88 units not using morphine, 20 used an alternative opioid, with 12 giving diamorphine as the sole agent for sedation, and eight using fentanyl either alone $(n=4)$ or in combination with suxamethonium $(n=1)$, atracurium $(n=1)$, and diazepam $(n=2)$. Benzodiazepines were used for sedation before intubation by 16 units, all of whom routinely ventilated. Ten used diazepam (four alone, four with morphine, two with fentanyl) and six used midazolam (four alone, two with morphine). One surgical unit used ketamine, in combination with suxamethonium and vecuronium. One transferring unit used phenobarbitone.

Muscle relaxants were used by $19 / 88$ units (22\%); all co-administered sedative drugs (table 3). Table 4 documents the substantial variation in prescribed doses between units.

\section{Discussion}

Neonates respond adversely to various neonatal intensive care practices ${ }^{11}{ }^{12}$ and several investigators have studied the physiological responses of neonates to awake intubation, ${ }^{2} 589$ reporting significant rises in systemic arterial blood pressure and intracranial pressure, as well as significant falls in heart rate and transcutaneous oxygen tensions or saturations. Concern has also been raised about the contribution of raised intracranial pressure ${ }^{4-13}$ to the aetiology of intraventricular haemorrhage.

Premedication can improve or abolish these potentially deleterious responses. Bradycardia can be abolished by the use of atropine ${ }^{2}$ or glycopyrrolate, ${ }^{7}$ while rises in intracranial pressure have been attenuated by using muscle relaxants alone ${ }^{269}$ and combined with intra- 
venous anaesthetics. ${ }^{45}$ Friesen $e t$ al ${ }^{4}$ reported a mean increase in anterior fontanelle pressure of $197 \%$ in one group of premature neonates who were intubated awake compared with $25 \%$ in a matched second group, who received premedication before intubation. The use of suxamethonium can shorten the procedure of intubating neonates, ${ }^{67}$ thus reducing the incidence and duration of the hypoxaemia that commonly occurs. ${ }^{23}$

This study is an accurate representation of the current state of UK practice on premedication for intubation. The questionnaire was quick and easy to administer, with unambiguous questions, each addressing a single point, and requiring simply a yes or no response in most cases. Only two people made calls, thus achieving a high level of consistency in the application of the questionnaire, and a $99 \%$ response rate. The weaknesses of the study design lie in the potential for inaccurate information to be given over the telephone or recorded afterwards, and for the subject matter of the study to bias the responses. However, such a bias should increase positive responses. The brevity and closed design of the questionnaire sought to minimise all these problems.

These results show that most UK units do not premedicate before intubation. Our findings are similar to those of Ziegler and Todres. ${ }^{10}$ Reasons were not formally documented, but many commented that there wasn't time, particularly in an emergency reintubation. This has not been the experience in our unit and only in exceptional cases has it not been possible to ventilate using a bag-valve-mask or T piece while premedication is prepared. All doctors should be able to maintain an airway and hand ventilate after appropriate training. The use of local guidelines and protocols should mitigate any anxiety over the use of potent sedative and anaesthetic drugs by junior doctors. In practice, elective intubations by inexperienced juniors should be supervised and emergency intubations are likely to be performed by a more experienced operator. Barrington and Byrne ${ }^{16}$ have recently reported on the safety and practicability of premedicating 253 neonates for intubation, using a regimen of atropine, fentanyl, and suxamethonium, in a unit with the variable skill mix and experience that is inevitable in daily practice.

In those units that do premedicate, morphine remains the most popular choice. This may be due to familiarity, although the wide range of doses of morphine recorded in table 4 suggests that some operators use homeopathy to avoid prolonged respiratory depression while others use much larger doses to try to accelerate the slow onset of effect. However, there are several drugs that are better than morphine in terms of speed of onset, duration of effect, and side effect profile. Fentanyl and alfentanil are potent opioids with a rapid onset and short duration of action when given as a bolus. Barrington's regimen, ${ }^{16}$ using fentanyl $3-4 \mathrm{mcg} / \mathrm{kg}$ produced chest wall rigidity as the only side effect in just 4/253 neonates and three resolved promptly with the administration of suxamethonium. This side effect seems to be related to peak plasma concentration and can be minimised by slow bolus administration. ${ }^{17}$

Diazepam has a rapid onset of action and causes little haemodynamic or respiratory depression in isolation, but it and its active metabolites have long half lives. Midazolam is less problematic in this respect, but has been reported to be associated with myoclonic activity when given as a bolus ${ }^{18}$ and possibly with fits in preterm neonates when given too rapidly. ${ }^{19} 20$

Of the induction agents, propofol is widely used before intubation in children and infants, although there are no published data on experience in neonatal units. Ketamine offers cardiorespiratory stability but may raise intracranial pressure, which makes it less suitable. Barbiturates are not widely used, although methohexitone has been studied. ${ }^{21}$ They are rapidly effective but have prolonged elimination half lives.

Only $22 \%$ of units using any sedation also used neuromuscular blockade before intubating. Encouragingly, all muscle relaxants were accompanied by sedation. Most units used a short acting agent. Suxamethonium is still the most rapidly acting relaxant available and has important safety benefits in clinical practice where variations in skill and experience are inevitable. Half the units using suxamethonium did not coadminister a vagolytic drug to pre-empt the potential profound bradycardia that may be associated with suxamethonium, especially if given more than once. We did not enquire whether a vagolytic was drawn up ready in these nine units.

Currently $63 \%$ of UK neonatal units give no sedation before intubation on their unit. Only $14 \%$ have a protocol for premedication before intubation and only $8 \%$ use it for elective and emergency reintubations on the unit. This is despite an increasing body of research which supports this practice, on the grounds that it helps to maintain physiological homeostasis, may mitigate against risk factors for intraventricular haemorrhage, and reduces the time taken to intubate. There is also no evidence that sedation before intubation is less appropriate in neonates than in adults and children, in whom awake intubation would not be tolerated. While further studies are necessary to establish the optimal drug regimen and doses, there is sufficient evidence to support the routine practice of neonatal premedication prior to elective intubation.

1 King BD, Harris LC Jr., Greifenstein FE, Elder JD Jr, Dripps RD. Reflex circulatory responses to direct laryngoscopy and tracheal intubation performed during general anaesthesia. Anesthesiology 1951;12:556-66.

2 Kelly MA, Finer NN. Nasotracheal intubation in the neonate: Physiologic responses and effects of atropine and neonate: Physiologic responses and effect

3 Marshall TA, Deeder R, Pai S, Berkowitz GP, Austin TL. Physiologic changes associated with endotracheal intubation in preterm infants. Crit Care Med 1984;12:501-3.

4 Friesen RH, Honda AT, Thieme RE. Changes in anterior fontanel pressure in preterm neonates during tracheal intubation. Anesth Analg 1987;66:874-8.

5 Stow PJ, McLeod ME, Burrows FA, Creighton RE. Anterior fontanelle pressure responses to tracheal intubation in the awake and anaesthetized infant. $\mathrm{Br} \mathcal{F}$ Anaesth 1988;60:167-70.

6 Barrington KJ, Finer NN, Etches PC. Succinylcholine and atropine for premedication of the infant before nasotracheal intubation: a randomised, controlled trial. Crit Care Med 1989;17:1293-6. 
7 Pokela M-L, Koivisto M. Physiological changes, plasma $\beta$-endorphin and cortisol responses to tracheal intubation in neonates. Acta Paediatr 1994;83:151-6.

8 Millar C, Bissonnette B. Awake intubation increases intracranial pressure without affecting cerebral blood flow velocity in infants. Can $\mathcal{F}$ Anaesth 1994;41:281-7.

9 Raju TNK, Vidyasagar D, Torres C, Grundy D, Bennett EJ. Intracranial pressure during intubation and anaesthesia in infants. F Pediatr 1980;96:860-2.

10 Ziegler JW, Todres ID. Intubation of newborns (letter). $A m$ f Dis Child 1992;146:147-9.

11 Omar SY, Greisen G, Ibrahim MM, Youssef AM, FriisHansen B. Blood pressure responses to care procedures in
ventilated preterm infants. Acta Paediatr Scand 1985;74:920-4.

12 Greisen G, Frederiksen PS, Hertel J, Christiansen NJ. Catecholamine response to chest physiotherapy and endotracheal suctioning in preterm infants. Acta Pediatr Scand 1985;74:525-9.

13 Donn SM, Philip AGS. Early increase in intracranial pressure in preterm neonates. Pediatrics 1978;61:904-7.

\section{Commentary}

It is impossible to intubate an awake adult without adequate analgesia or sedation; attempts to do so produce a variety of undesirable and sometimes harmful pathophysiological responses. In contrast, awake intubation of a neonate remains common practice, despite mounting evidence that it is painful, stressful, and potentially damaging.

Some neonatal units now use anaesthetic or analgesic drugs before laryngoscopy, but it is clear from the article by Whyte et al that there is no consensus on this. A reluctance to use anaesthesia might be because of fears that the drugs themselves could be harmful, or that it is not feasible to give these drugs in acute care.

Duncan et al have reviewed the published data on neonatal intubation, and it is clear that aminsitration of sedative, analgesic, or anaes-
14 McDonald MM, Kloops BL, Johnson ML, et al. Timing and antecedents of intracranial hemorrhage in the newborn. antecedents of intracra
Pediatrics 1984;74:32-6.

15 Bada HS, Miller JE, Menke JA, et al. Intracranial pressure and cerebral arterial pulsatile flow measurements in neonatal intraventricular hemorrhage. $\mathcal{F}$ Pediatr 1982;100:291-6.

16 Barrington KJ, Byrne JB. Premedication for neonatal intubation. Am f Perinatol 1998;15:213-16.

17 Streisand JB, Bailey PL, LeMaire L, et al. Fentanyl-induced rigidity and unconsciousness in human volunteers. $A n-$ esthesiology 1993;78:629-34

18 Magny JF, d'Allest AM, Nedelcoux H. Midazolam and myoclonus in neonates. Eur f Pediatr 1994;153:389-92.

19 Van den Anker JN, Sauer PJJ. The use of midazolam in the preterm neonate. Eur f Pediatr 1992;151:152.

20 Birrell VL, Wyllie JP, Pagan J. Midazolam causing convulsions. Br f Intensive Care (In press).

21 Naulers G, Deloof E, Vanhole C, Kola E, Devlieger H. Use of methohexital for elective intubation in neonates. Arch Dis Child Fetal Neonatal Ed 1997;77:F61-4.

thetic drugs can make intubation easier to perform and also avoid the hypoxia and haemodynamic consequences associated with awake intubation. However, two issues are unclear. First, which is the most appropriate drug or drugs for elective neonatal intubation, and secondly, what techniques are available for the neonate requiring semi-urgent intubation in the delivery room. It is surprising that despite the current interest in neonatal sedation and analgesia, so few data are available on the provision of effective analgesia and anaesthesia for neonatal intubation.

Paediatric Intensive Care Unit

ANDREW WOOLF Bristol Royal Hospital for Sick Children

St Michael's Hill

Bristol BS2 8BF 